\title{
Electrical stimulation and biofeedback for the treatment of fecal incontinence: a systematic review
}

\author{
Reinhard Vonthein • Tankred Heimerl • \\ Thilo Schwandner • Andreas Ziegler
}

Accepted: 24 June 2013 / Published online: 31 July 2013

(C) The Author(s) 2013. This article is published with open access at Springerlink.com

\begin{abstract}
Purpose This systematic review determines the best known form of biofeedback (BF) and/or electrical stimulation (ES) for the treatment of fecal incontinence in adults and rates the quality of evidence using the Grades of Recommendation, Assessment, Development, and Evaluation. Attention is given to type, strength, and application mode of the current for ES and to safety.

Methods Methods followed the Cochrane Handbook. Randomized controlled trials were included. Studies were searched in The Cochrane Library, MEDLINE, and EMBASE (registration number (PROSPERO): CRD42011001334).

Results BF and/or ES were studied in 13 randomized parallelgroup trials. In 12 trials, at least one therapy group received $\mathrm{BF}$ alone and/or in combination with ES, while ES alone was evaluated in seven trials. Three (four) trials were rated as of high (moderate) quality. Average current strength was reported in three of seven studies investigating ES; only two studies reached the therapeutic window. No trial showed superiority of control, or of BF alone or of ES alone when compared with
\end{abstract}

Electronic supplementary material The online version of this article (doi:10.1007/s00384-013-1739-0) contains supplementary material, which is available to authorized users.

R. Vonthein · A. Ziegler $(\bowtie)$

Institut für Medizinische Biometrie und Statistik, Universität zu Lübeck, Universitätsklinikum Schleswig-Holstein, Campus Lübeck, Ratzeburger Allee 160, Haus 24, 23562 Lübeck, Germany

e-mail: ziegler@imbs.uni-luebeck.de

R. Vonthein · A. Ziegler

Zentrum für Klinische Studien Lübeck, Universität zu Lübeck,

Lübeck, Germany

T. Heimerl $•$ T. Schwandner

Klinik für Allgemein-, Viszeral-, Thorax-, Transplantations- und

Kinderchirurgie, Zentrum für minimalinvasive Chirurgie,

Universitätsklinikum Gießen und Marburg $\mathrm{GmbH}$, Standort

Gießen, Gießen, Germany
$\mathrm{BF}+\mathrm{ES}$. Superiority of BF + ES over any monotherapy was demonstrated in several trials. Amplitude-modulated mediumfrequency (AM-MF) stimulation, also termed pre-modulated interferential stimulation, combined with $\mathrm{BF}$ was superior to both low-frequency $\mathrm{ES}$ and $\mathrm{BF}$ alone, and $50 \%$ of the patients were continent after 6 months of treatment. Effects increased with treatment duration. Safety reporting was bad, and there are safety issues with some forms of low-frequency ES.

Conclusions There is sufficient evidence for the efficacy of $\mathrm{BF}$ plus ES combined in treating fecal incontinence. AM-MF plus BF seems to be the most effective and safe treatment.

Key Messages

- The higher the quality of the randomized trial the more likely was a significant difference between treatment groups.

- Two times more patients became continent when biofeedback was used instead of a control, such as pelvic floor exercises.

- Two times more patients became continent when biofeedback plus electrical stimulation was used instead of biofeedback only.

- Low-frequency electrical stimulation can have adverse device effects, and this is in contrast to amplitudemodulated medium-frequency electrical stimulation.

- There is high quality evidence that amplitude-modulated medium-frequency electrical stimulation plus electromyography biofeedback is the best second-line treatment for fecal incontinence.

Keywords Conservative treatment · Biofeedback · Cleveland Clinic score $\cdot$ Electrical stimulation .

Fecal incontinence $\cdot$ Meta-analysis
Abbreviations
ADE Adverse device effect
AM-MF Amplitude-modulated
medium-frequency stimulation 


$\begin{array}{ll}\text { ANOVA } & \text { analysis of variance } \\ \text { BF } & \text { Biofeedback } \\ \text { CCS } & \text { Cleveland Clinic score } \\ \text { CI } & \text { Confidence interval } \\ \text { EMG } & \text { Electromyography } \\ \text { ES } & \text { Electrical stimulation } \\ \text { FIQoL } & \text { Fecal incontinence quality } \\ & \text { of life } \\ \text { LFS } & \text { Low-frequency stimulation } \\ \text { PFE } & \text { Pelvic floor exercises } \\ \text { QoL } & \text { Quality of life } \\ \text { RCT } & \text { Randomized controlled trial } \\ \text { RR } & \text { Relativ risk } \\ \text { SAE } & \text { Serious adverse event }\end{array}$

\section{Introduction}

Approximately $1 \%$ of adults suffer from uncontrolled loss of stool $[1,2]$. Very few guidelines for managing fecal incontinence in adults are available, and one of these was issued by the National Institute for Health and Clinical Excellence for UK in 2007 [3]. In general, the first-line therapy may try to solidify liquid stools with fiber elements or medications [4]. The specialized management usually applies nonsurgical methods, such as pelvic floor exercises (PFE), biofeedback (BF), and electrical stimulation (ES) [3], to improve the strength and coordination of the sphincter muscles. However, the internal anal sphincter consists of smooth muscles and is not amenable to voluntary exercises. Furthermore, it is difficult to actively reach the slow-twitch type I fibers [5, 6]. It thus makes sense to use ES on the smooth and slow muscular components.

When judging the efficacy of the ES treatment or the combination of BF and ES (BF + ES), current type, current strength, and application mode are essential [6-10], as recently discussed by Schwandner et al. [11].

For example, Telford and colleagues [5] demonstrated that the motorical threshold for sphincter muscles with lowfrequency electrical stimulation (LFS) is around $20 \mathrm{~mA}$. Specifically, they used the strength-duration test to measure the current strength required for visible muscle contraction at different pulse durations. They first found that the current intensity at $1 \mathrm{~ms}$ pulse duration was the best predictor of incontinence [5]. Furthermore, in their control group [12], they observed that a currency of $18.2 \mathrm{~mA}(90 \%$ reference interval $\geq 19 \mathrm{~mA}$ ) was required at $1 \mathrm{~ms}$ pulse duration for muscle contraction.

LFS, as used in most studies of fecal incontinence, can be very painful when applied to the pelvic floor exercises [13-15], and it can cause adverse device effects (ADE) [13]. Surprisingly, this relationship between pulse configuration, voltage amplitudes, and physiological outcome has not been addressed in any of the systematic reviews on ES for fecal incontinence, although it is well known in biomedical engineering [6-10]. It was also neglected in some two-group randomized trials where two ES stimulations were compared and both ES were below the threshold for effectiveness [13]. Stimulation with alternating current at medium frequency (MF $>1,000 \mathrm{~Hz}$; amplitude-modulated medium frequency: AM-MF), also termed pre-modulated interferential ES in the literature, does not have the disadvantage of LFS because its biological effect is based on a different principle than the allor-nothing effect of LFS [16]. Previous systematic reviews [Supplementary Table S1;17-19] did not distinguish between LFS and MF therapies.

The systematic reviews focused either on ES [17] or on $\mathrm{BF}[18,19]$, but they did not consider ES + BF to be a combination therapy which would be important for treatment guidelines. Here, we aim at identifying the best second-line conservative treatment, consisting in $\mathrm{BF}, \mathrm{ES}$, or $\mathrm{BF}+\mathrm{ES}$ by taking into account the type, strength, and application mode of current. We specifically address duration-response relationships which were not correctly reported in previous reviews [19] and safety issues. By finally grading the evidence [20], we provide valuable aid to decision making in a guideline for fecal incontinence.

\section{Methods}

The protocol to this systematic review was published in PROSPERO (CRD42011001334) on June 1, 2011. A detailed description of the methods can be found in the Electronic supplementary material. In brief, we included randomized controlled parallel-group trials of BF or ES or BF + ES in adults in need of a second-line conservative treatment and no obvious need for surgery for fecal incontinence reporting patient-related outcome, i.e., remission, response, or disease-related quality of life (QoL) on validated scales as assessed by two reviewers in consensus. Data extraction followed recommendations of the Cochrane Handbook for Systematic Reviews of Intervention [21]; for details, see Electronic supplementary material.

Excluded studies and reasons for exclusion are summarized in Supplementary Table S2. Supplementary Tables S3 and S4 provide details on populations, interventions, comparator, outcome, and design of included studies to find matching entries for meta-analysis. Safety issues were coded as serious adverse events (SAE) and adverse device effects (ADE), both according to ISO 14155:2011.

The $2 \times 2$ treatment scheme has been analyzed using an analysis of variance meta-analysis (meta-ANOVA) [22] for the endpoint remission using the relative risk (RR) as effect measure. Results were graded high, moderate, or low quality using the Grades of Recommendation, Assessment, Development, and Evaluation (GRADE) [20]. 


\section{Results}

Study selection

We identified 128 potentially relevant studies from titles and abstracts (Supplementary Fig. S1), including several systematic reviews (Supplementary Table S1) [4, 17, 19, 23-36]. Twenty-three studies were retrospective chart reviews or prospective case series [37-59], and four current trials [60-63] were found in trial registries, but not in the literature. Seven RCTs [15, 64-69] met at least one exclusion criterion (Supplementary Table S2), and 13 RCTs remained [11, 14, 16, 18, 70-78] (Supplementary Tables S3 to S5).

\section{Qualitative summary}

We identified two different groups of patients in the RCTs. The first group of studies predominantly included younger mothers $[70,73,74]$, but females only $[16,75]$, and the second group included patients of all ages (predominantly elderly) and both sexes (predominantly women) [11, 14, 16, 71, 72, 76-78]; Supplementary Text 2 of the Electronic supplementary material. In one of the 13 RCTs [78], the active ES treatment and the active ES placebo had 2.3 and $0.13 \mathrm{~mA}$ current and were substantially below the therapeutic window of about $20 \mathrm{~mA}$ [5].

The quality of the RCTs varied substantially (Supplementary Table S3), and Fig. 1 shows that there was a strong correlation between trial quality and group size $(r=0.81$; $p=0.0007)$. Furthermore, significant trials tended to be of better quality (one-sided, $p=0.0299$ ) and to have a larger group size (one-sided, $p=0.0450$ ).

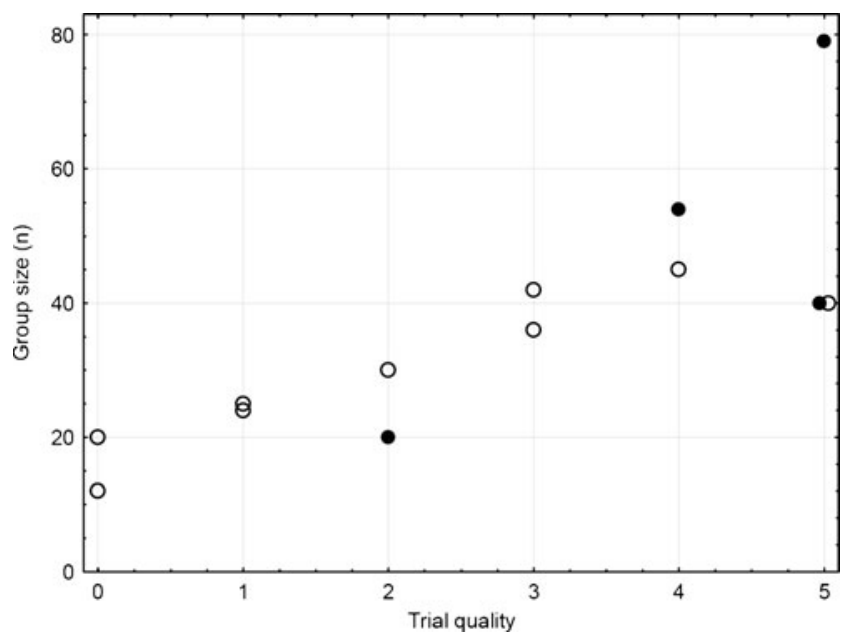

Fig. 1 Quality of trials by sample size per group. Full and open circles display randomized controlled trials with and without significant differences between treatment groups, respectively. There is a clear correlation between group size and quality of trials. Significant trials tend to be of better quality (one-sided, $p=0.0299$ ) and tend to have a larger group size (one-sided, $p=0.0450$ )
Only three of the 13 trials $[11,72,77]$ fulfilled all quality criteria; the other trials may have incurred biases. For example, intention-to-treat (ITT) analyses were performed in the absence of a validated outcome measure or a masked assessor in some trials $[14,18,73,78]$, and these studies were considered as moderate quality evidence. Good and moderate quality studies reported adequate randomization procedures and case number determinations. Other trials [16, 70, 71, 74-76] were considered as low quality. Several reasons lead to a downgrading of these trials. For example, the RCT by Heymen [76] was lacking of a validated score, it had a large variability due to small sample size, and $20 \%$ of the patients were missing in three of four groups. Figure 2 summarizes treatments and effects after exclusion of low-quality trials and trials with too low current; see Supplementary Fig. S2 for all trials. Figure S3 displays effect sizes and $95 \%$ confidence intervals $(\mathrm{CI})$ for all trials. First, no trial showed superiority of control. Second, no trial showed superiority of any monotherapy, when compared with BF + ES. The longer and more intensive the treatment the stronger were the effects (Supplementary Tables S4 and S5). This finding holds both within and across trials.

\section{Quantitative data summary}

For meta-analysis, we chose the remission rate because it was the endpoint with the greatest patient relevance, and it was the most completely reported endpoint. Results were similar for other endpoints (Cleveland Clinic score (CCS): Table 1; $z$ scores for any validated outcome: Supplementary Table S5).

The meta-ANOVA of at least medium-quality trials showed the tendency for inferiority for ES when compared with $(\mathrm{RR}=0.47 ; 95 \% \mathrm{CI}, 0.13-1.72 ; p=0.25)$ and superiority of $\mathrm{BF}$ over control $(\mathrm{RR}=2.35 ; 95 \% \mathrm{CI}, 1.33-4.16$; $p=0.0033$ ) (Table 2). The combination therapy $\mathrm{BF}+\mathrm{ES}$ was superior to both $\mathrm{BF}(\mathrm{RR}=2.12 ; 95 \% \mathrm{CI}, 1.42-3.16$; $p=0.00022)$ and $\mathrm{ES}(\mathrm{RR}=22.97 ; 95 \% \mathrm{CI}, 1.81-291.69$; $p=0.016$ ) (Table 2). No positive results on ES versus BF or control emerged. RRs for BF over control and for ES on top of BF over BF were close to 2 when all trials were included, when adjustments were made for treatment duration or duration of continence.

When AM-MF ES was considered to be a different therapy concept from LFS, similar results were obtained (Supplementary Table S6). Specifically, both LFS and the combination of LFS and BF were not superior to not doing these therapies ( $p=0.96$ and $p=0.49$ ), while $\mathrm{BF}$ alone and the combination of $\mathrm{AM}-\mathrm{MF}+\mathrm{ES}$ were superior to not doing these therapies $(p=0.005$ and $p=0.002$; Supplementary Table S6).

EMG-BF plus AM-MF ES sent 42 and $54 \%$ of patients into remission [11, 72], $75 \%$ of patients were asymptomatic with the combination of BF and LFS in [73], $27 \%$ 


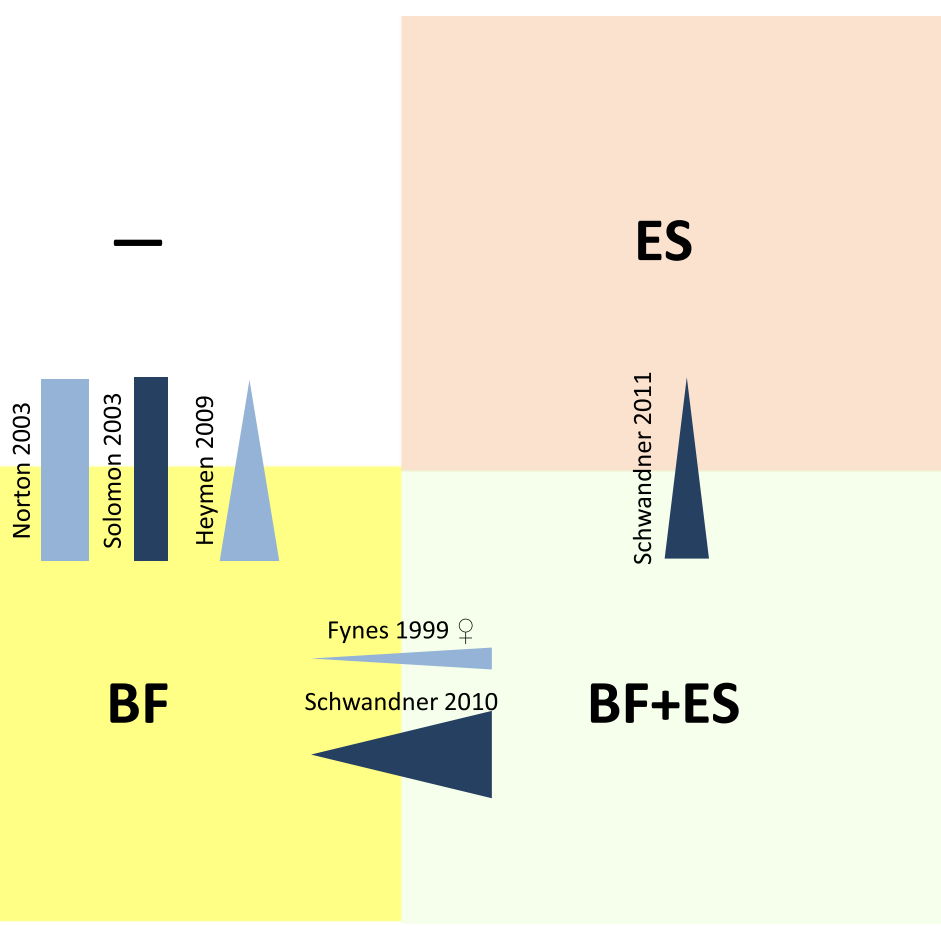

Fig. 2 Results and quality of clinical trials, with at least moderate quality of biofeedback $(B F)$, sufficient electrical stimulation $(E S)$, or biofeedback plus electrical stimulation $(B F+E S)$. A triangle denotes significant difference between two stimulation modes; a bar represents not statistically significant difference. Trial quality is color coded: moderate, Size of bars or triangles is proportional to case numbers ranging from 40

completely asymptomatic in [74], and no patient cured in [16]. Different modes of BF brought between 20 and $54 \%$ remissions $[72,73,75,76]$. LFS yielded the worst remission rates which varied between 0 and $4 \%[11,16,70,78]$.

\section{Safety}

Reporting of adverse events was patchy, not in accordance with definitions [71], and SAEs were reported in the text or in flow charts of only three trials: 2 in 15 patient years of insufficient or sham ES [78], 5 in 64 patient years of BF or control [18], 8 in 59 patient years of EMG-BF plus AM-MF ES, and 5 in 59 patient years of EMG-triggered stimulation [72]. This indicates homogeneous populations with 0.15 disruptive SAE per patient year. ADEs that led to treatment discontinuation were reported for a total of 31 cases $(5.6 \%)$ in seven trials with 728 participants $[11,14,18,71,72,78,79]$ and in one description of lowfrequency ES [13]. Nondisruptive ADEs were reported in one trial [11], the persisting pain is close to half of patients using LFS and none using AM-MF stimulation.

Grading the quality of evidence

The number of patients in remission is considered to be a valid and patient-relevant endpoint as are validated incontinence
[73] to 171 [18]. For example, the trial by Heymen and colleagues [14] is of moderate quality, demonstrated superiority of BF over PFE alone, and a total of 108 patients were randomized in the trial. The off-diagonals represent the two monotherapies, the top left represents control and includes pelvic floor exercises (PFE) or some other standard therapy which is neither $\mathrm{BF}$ nor ES. The bottom right represents the combination therapy BF + ES

scores when masked observers are used and when data are analyzed on an ITT basis. However, the definition of remission differed across trials. It was described as asymptomatic [73], completely asymptomatic [74], best possible effect on a 10-point scale [70], no accident in 1 week [14, 18, 75, 76], a score of 0 in an incontinence scale when asked about the last 30 days $[11,71,72]$, and cured $[16,18,78]$. The different definitions had an effect on the proportion of missing data which was as large as $39 \%$ because of the incompleteness of patient diaries [18].

One aspect for grading quality of trials is duration-response gradients. Two trials reported assessments in 3-month intervals, and a duration-response gradient could be observed [80]. Specifically, the longer the treatment the more patients were in remission and scored better treatment response.

\section{Risk of bias across studies}

There are two obvious sources of heterogeneity between studies. First, the spectrum of patients included in the trials was diverse. Trials in predominantly younger mothers cannot be compared with trials in elderly patients of both sexes despite of the different etiology in these patients. And there are other inclusion/exclusion factors which might be prognostic for treatment effect. Anatomic defect or inflammatory 
Table 1 Remission rate (in \%) and duration and response (change in Cleveland Clinic score) by treatment group and trial quality for control, biofeedback, electrical stimulation, and combination of BF and ES

\begin{tabular}{|c|c|c|c|c|c|c|}
\hline \multicolumn{2}{|c|}{ Remission } & \multirow{2}{*}{$\begin{array}{l}\text { CCS } \\
\text { change }\end{array}$} & \multirow[t]{2}{*}{ Quality } & \multirow[t]{2}{*}{ Treatment } & \multirow[t]{2}{*}{ Cases } & \multirow[t]{2}{*}{ Trial } \\
\hline$[\%]$ & Duration & & & & & \\
\hline 54 & 1 month & -7 & high & AM-MF ES + BF (EMG) & 40 & Schwandner 2011 [72] \\
\hline 42 & 1 month & -8 & high & AM-MF ES + BF (EMG) & 79 & Schwandner 2010 [11] \\
\hline 75 & - & - & moderate & $\mathrm{LFS}+\mathrm{BF}(\mathrm{EMG})+\mathrm{PFE}$ & 20 우 & Fynes 1999 [73] \\
\hline 27 & - & -2 & low & $\mathrm{LFS}+\mathrm{BF}(\mathrm{EMG})+\mathrm{PFE}$ & $30 q$ & Mahony 2004 [74] \\
\hline 0 & - & -5.5 & low & $\mathrm{LFS}+\mathrm{BF}(\mathrm{EMG})$ & 24 & Healy 2006 [16] \\
\hline 20 & 1 month & -5 & high & BF (EMG) & 79 & Schwandner 2010 [11] \\
\hline $8 \mid 39$ & cured $\mid 1$ week & - & moderate & $\mathrm{BF}(\mathrm{EMG})+\mathrm{PFE}+\mathrm{Edu}$ & 42 & Norton 2003 [18] \\
\hline $4 \mid 39$ & cured $\mid 1$ week & - & moderate & $\mathrm{BF}$ (balloon) $+\mathrm{PFE}+\mathrm{Edu}$ & 49 & Norton 2003 [18] \\
\hline 44 & 1 week & - & moderate & $\mathrm{BF}$ (balloon) $+\mathrm{PFE}+\mathrm{Edu}$ & 45 & Heymen 2009 [14] \\
\hline 35 & - & - & moderate & $\mathrm{BF}$ (balloon) $+\mathrm{PFE}$ & 20 우 & Fynes 1999 [73] \\
\hline 19 & 1 month & -6.5 & low & $\mathrm{BF}$ (balloon) + PFE & 72 & Bartlett 2011 [71] \\
\hline 54 & 1 week & - & low & $\mathrm{BF}$ (balloon) + Edu & 11 우 & Ilnyckyj 2005 [75] \\
\hline$\geq 40$ & 1 week & - & low & $\mathrm{BF}(\mathrm{EMG})+\mathrm{ST}+\mathrm{Edu}$ & 10 & Heymen 2000 [76] \\
\hline$\geq 20$ & 1 week & - & low & $\mathrm{BF}(\mathrm{EMG})+\mathrm{Edu}$ & 10 & Heymen 2000 [76] \\
\hline$\geq 20$ & 1 week & - & low & $\mathrm{BF}(\mathrm{EMG})+\mathrm{ST}+\mathrm{Edu}$ & 10 & Heymen 2000 [76] \\
\hline 20 & 1 week & - & low & $\mathrm{BF}(\mathrm{EMG})+\mathrm{Edu}$ & 10 & Heymen 2000 [76] \\
\hline 20 & - & -2 & low & $\mathrm{BF}(\mathrm{EMG})+\mathrm{PFE}$ & 30 웅 & Mahony 2004 [74] \\
\hline 4 & - & -1 & low & BF (EMG) & $24+$ & Naimy 2007 [70] \\
\hline $0 \mid 39$ & cured $\mid 1$ week & - & moderate & $\mathrm{PFE}+\mathrm{Edu}$ & 43 & Norton 2003 [18] \\
\hline $0 \mid 39$ & cured $\mid 1$ week & - & moderate & Edu & 37 & Norton 2003 [18] \\
\hline 0 & cured & - & moderate & LFS (Sham) + PFE & 43 & Norton 2005 [78] \\
\hline 21 & 1 week & - & moderate & $\mathrm{PFE}+\mathrm{Edu}$ & 63 & Heymen 2009 [14] \\
\hline 41 & 1 week & - & low & Edu & $12+$ & Ilnyckyj 2005 [75] \\
\hline 0 & 1 month & +1 & high & LFS & 40 & Schwandner 2011 [72] \\
\hline 2 & cured & - & moderate & $\mathrm{LFS}+\mathrm{PFE}$ & 47 & Norton 2005 [78] \\
\hline 4 & - & -4.8 & low & LFS & 24 & Healy 2006 [16] \\
\hline 0 & - & -1 & low & LFS & $25 q$ & Naimy 2007 [70] \\
\hline
\end{tabular}

$A M-M F E S$ amplitude-modulated medium-frequency stimulation, + plus, $B F$ biofeedback, $E M G$ electromyography, - not reported, $L F S$ lowfrequency electrical stimulation, $P F E$ pelvic floor exercises, $q$ recent mothers, $E d u$ education, $S T$ sensory training, $B F$ biofeedback, $E S$ electrical stimulation, $E S+B F$ combination of $\mathrm{BF}$ and $\mathrm{ES}$

Table 2 Meta-analysis results from two-way analysis of variance for remission for all trials of at least moderate quality. Electrical stimulation tended to be inferior to control, while biofeedback was superior to control. The combination therapy BF + ES was superior to both monotherapies

\begin{tabular}{lrll}
\hline Comparison & \multicolumn{1}{l}{ RR } & $95 \% \mathrm{CI}$ & $p$ \\
\hline ES vs. control & 0.47 & $0.13-1.72$ & 0.25 \\
BF vs. control & 2.35 & $1.33-4.16$ & 0.0033 \\
BF + ES vs. BF & 2.12 & $1.42-3.16$ & 0.00022 \\
BF + ES vs. ES & 22.97 & $1.81-291.69$ & 0.016 \\
\hline
\end{tabular}

Heterogeneity $\tau^{2}<0.0001$ (95\% CI: $0.00-0.25 ; p=0.4830$ ). The metaanalysis included six trials: [71, 76] compared only two modes of BF; [77] did not report data on remission.

$R R$ relative risk, $C I$ confidence interval, $E S$ Electrical stimulation, $B F$ biofeedback chronic bowel disease was an explicit exclusion criterion in some studies [77], while these patients were included in other trials [14]. Previous anorectal surgery and anal sphincter damage were classified differently across studies, and the extent of heterogeneity remained unclear after data extraction.

Second, the treatment forms varied substantially (Supplementary Table S4), and the most important differences were type of treatment, patient position, and intensity of first- and second-line treatment. ES studies differed in treatment duration and average current which sometimes was even below the treatment window.

Six included trials were found in public registries [81-86]. Selection or publication biases were not apparent. Registration information and consistency between information in the registry and the published report needs improvement. 
Specifically, in four trials, there was no information or inconsistent information on primary and secondary outcomes. The primary endpoint was altered in two trials $[14,72]$, in both trials for very good reasons.

\section{Discussion}

Following up on promising results of the combination of ES with $\mathrm{BF}$, this systematic review revealed more, high-quality evidence than previous reviews because of the publication of several new trials [11, 14-16, 70-72, 87]. The clinical development of BF and ES can be grouped into three general phases. In the first phase, diverse case series were reported, and those had to be excluded from this systematic review.

In the second phase, narrow patient populations were studied. Specifically, fecal incontinence in younger females after delivery was considered in several trials [70, 73-75]. Outcome measures included patient diary and manometry. While manometry does not adequately reflect treatment response [16], diaries were incomplete with missing data as high as $39 \%$ [18]. To avoid missing data in questionnaires, patients are nowadays asked about continence/incontinence in the recent past, such as the preceding week or month.

In the third phase, several RCTs studied the intensity, duration, and the mode of BF and ES treatments. BF was given optically or acoustically, signaling change in pressure, in electromyogram $(E M G)$ or ultrasound. EMG devices for home use were developed so that daily sessions at home were added to sessions with a therapist. ES used different frequencies and current strengths. Such "dose finding" sometimes required more than two treatment groups. The studies tended to be small so that not all comparisons were significant. The combination BF + ES was studied in recent RCTs of higher quality, which included sufficiently large numbers of patients, investigated several patient relevant endpoints at the final follow-up and also reported changes over time.

Two high-quality RCTs showed a consistently efficacious combination of AM-MF ES plus EMG-BF with $50 \%$ patients being continent after 6 or 9 months of treatment. This treatment was consistently superior to low-frequency ES and to BF alone.

Two important aspects need to be addressed in future studies on fecal incontinence. First, an in-depth discussion on primary patient-relevant endpoint to be used is required. Specifically, Norton [88] argued that QoL should be the primary outcome. We do not agree with her conclusion. If the aim is to treat patients suffering from fecal incontinence, a successful treatment needs to make a patient continent. The degree of incontinence measured using a validated score, such as the CCS is semiquantitative and requires fewer study subjects than the dichotomous continent/incontinent endpoint. However, it is difficult to measure continence reliably because of different patient perceptions.
QoL is an important patient-related endpoint. If QoL is assessed in an elderly population suffering from fecal incontinence, the constructs determining their QoL need to be assessed reliably. For example, the fecal incontinence QoL questionnaire enquires sexual activities, traveling by plane or train, or eating out [89]. Patients seen in our own studies stated that these activities were not determining their QoL. The most important restrictions for their life was the personal stress caused by fecal incontinence, an important aspect was that whatever they did, the toilet had to be within reach [90]. There is a clear need for developing a reliable and valid QoL instrument for an elderly population suffering from fecal incontinence.

Remissions and responses were more frequent the longer the therapy lasted. This was demonstrated within two trials of highest quality and across trials. In consequence, both individual results and the synthesis could be graded higher.

In their recent systematic review, Norton and Cody [19] stated "No study reported any adverse events or deterioration in symptoms, ...". According to this systematic review, this statement needs to be corrected. Although reporting of safety was scarce, there were trials with SAEs, such as mortality, and even ADEs were reported in seven of 13 trials. Deterioration of symptoms was commonly reported as mean changes with standard deviations indicating a considerable proportion of changes for the worse. Specifically, [11] explicitly reported deterioration in $10.3 \%$ under AM-MF ES plus EMG-BF and $82.9 \%$ for LFS.

In their systematic review, Hosker and colleagues [17] stated that "electrical stimulation can cause a tissue reaction at the site of the electrodes. This usually resolves speedily when stimulation is stopped." This statement is in line with the findings of [11] who reported that approximately half of the patients receiving LFS treatment complained of pain during stimulation, and a quarter could not tolerate high currents required to reach the motor threshold. Some patients reported a feeling of pressure that persisted for hours after training. But these side effects in the trial were only minor ones due to thorough precautions which are not taken for granted in daily practice.

In separate work, we showed [13] that ADEs can occur with some devices. A major concern is the danger of tissue damage at the electrode/tissue interface. This is described in detail in the Supplementary Text 3 of the Electronic supplementary material.

Using the GRADE approach, we graded the quality of the trials and summarized the evidence (Table 3). In their recent review, Norton and Cody [19] stated that "treatment options for fecal incontinence have not yet been investigated by means of well-designed trials." The result of our systematic review is different. We have identified three well-designed randomized controlled trials of high quality $[11,72,77]$ and another three trials of medium quality and sufficient ES $[14,18,73]$.

One limitation of this review is that observational studies were excluded. Such quasi-randomized studies 


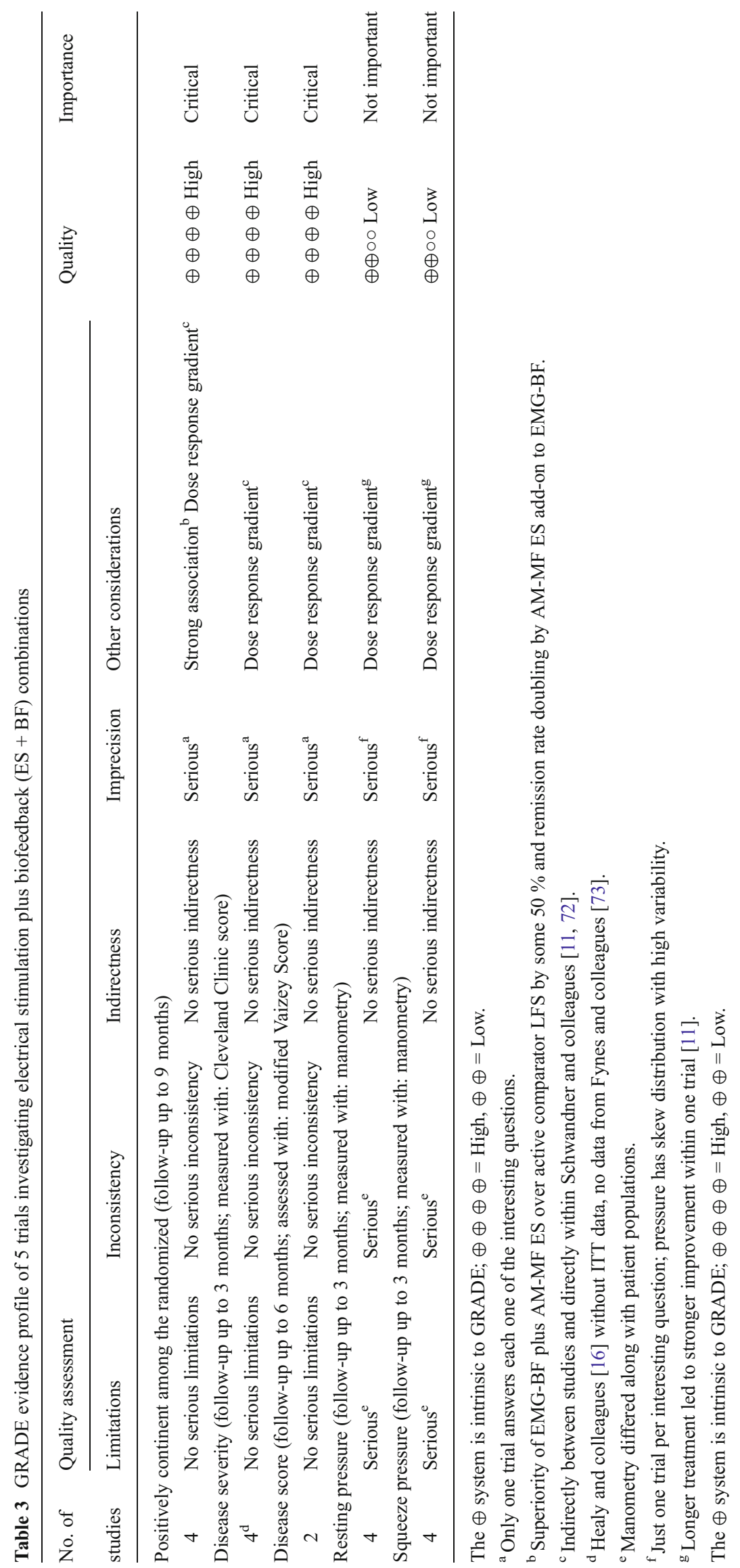


were considered as evidence of safe treatments involving properly working devices rather than evidence of efficacy. Furthermore, trial registries did not cover all trials before the 2008 version of the Declaration of Helsinki.

Despite these limitations, this systematic review is the first considering BF and ES to be a combination therapy, and in a supplementary analysis LFS was distinguished from AM-MF ES. An overview of the component treatments, their respective duration and intensity gradients is provided. Endpoints were weighted by grade of evidence to embed and support the results of pivotal trials. A first survey of safety is provided and discussed.

\section{Box}

Fecal incontinence

The anus is closed by the voluntary outer and the involuntary inner sphincter and the anal columns. Little pressure rests on these, as the rectum is folded by the voluntary musculus puborectalis. The muscles contract reflexively whenever pudendal and sacral nerves signal pressure. As continence is learned by toddlers, it can be forgotten and retrained. More common causes of fecal incontinence are damages to the muscles involved, particularly during delivery, or weaknesses of other parts involved, like rectocele, hemorrhoids, and prolapse.

\section{Biofeedback}

Biofeedback in a wider sense of a training aided by a realtime signal of proper functioning has been studied for decades. Pelvic floor exercises were augmented by such control. This facilitates the selective training of muscles one rarely contracts at will and does not discern during the normal defecation reflex.

Balloon manometers, electromyographs, ultrasound devices, and fingertips have been used as sensors. Signals are displayed usually on a screen or a line of light emitting diodes but may be given acoustically. Signal amplification needs to be adjustable to individual anatomy, conductivity and muscle strength at the time being.

When manometry studies are used to recalibrate the sensors of the rectum, this is sensory training and does not figure as biofeedback in this systematic review.

\section{Electrical stimulation}

Transcutaneous electrical stimulation (ES) comprises of pulses that trigger action potentials controlling muscle contraction. Contraction is sustained by perhaps 20 to 120 action potentials per second $(\mathrm{Hz})$. Pulses of that frequency are applied for some seconds at a time with some seconds rest in between. Regular training can lead to a buildup of muscle mass. A good anal electrode can reach both sphincters and the puborectalis muscle. The electrical current needs to be adjustable to electrical conductivity and pain tolerance. Unfortunately, pain sensors are stimulated too. They respond to the same low-frequency pulses. So, patients often do not tolerate currents high enough for muscle contraction.

AM-MF ES ( $1 \mathrm{kHz}$ to $1 \mathrm{MHz}$ ) elicits low-frequency action potentials, less pain and more natural muscle contractions [11].

EMG-triggered ES connects biofeedback to ES and is thought to condition proprioceptive motor control even before muscle buildup [11].

\section{Conclusions}

This systematic review demonstrated a superiority of BF over control and of the combination therapy BF + ES over BF and ES monotherapies. These findings were stable in sensitivity analyses. It was additionally found that LFS did not have a positive effect, either alone or in combination with BF. Both $\mathrm{BF}$ alone and AM-MF plus BF were superior to not doing these therapies. LFS has a risk for pain and a device-specific risk for tissue damage. There is sufficient evidence of high quality for a stronger recommendation for a certain treatment regimen of $\mathrm{BF}, \mathrm{ES}$, or $\mathrm{BF}+\mathrm{ES}$ to patients with fecal incontinence. Specifically, we conclude that the combination of AM-MF ES in an EMG-triggered application mode plus EMG-BF should gain a stronger recommendation as specialized management. BF deserves a weaker recommendation.

Acknowledgments Dr. Naimy added that biofeedback was given in a supine position. Dr. Heymen confirmed that treatment intensity was identical in Heymen et al. [76] and in Heymen et al. [14]. Dr. Whitehead confirmed that the trial registered as NCT00124904 was published as Heymen et al. [14]. Dr. Solomon reported recruitment of 300/350 patients as of November 2011 in the ongoing trial ANZCTRN12605000747628. The authors are grateful to Christiane Wichmann for her help with literature management and to Claudia Hemmelmann for valuable discussions.

Conflict of interest Thilo Schwandner was supported by the device manufacturer Procon GmbH Hamburg. In detail, Procon supplied all medical devices for biofeedback and electrical stimulation in the corresponding trials $[11,72]$ but no remuneration. Thilo Schwandner received a travel grant and course fee from Procon for a course on obstipation. He is a contracted flying doctor for device manufacturer Ethicon to perform STARR and Transtarr surgery for obstipation. He received honorariums from Ethicon for seminars in coloproctology and from the medical device vendor Cook for talks on fistula surgery plus a research grant. The Clinic for General, Visceral, Thorax and Transplantation Surgery, University of Gießen receives honorariums for 
hospitations in a coloproctology unit. All other authors declare no conflicting interests.

\section{References}

1. Nelson R, Norton N, Cautley E, Furner S (1995) Community-based prevalence of anal incontinence. JAMA 274(7):559-561

2. Perry S, Shaw C, McGrother C, Matthews RJ, Assassa RP, Dallosso H, Williams K, Brittain KR, Azam U, Clarke M, Jagger C, Mayne C, Castleden CM (2002) Prevalence of faecal incontinence in adults aged 40 years or more living in the community. Gut 50(4):480-484. doi:10.1136/gut.50.4.480

3. National Institute for Health and Clinical Excellence (2007) Faecal incontinence: the management of faecal incontinence in adults. Clinical Guideline CG49. http://www.nice.co.uk. Accessed 04 June 2011

4. Probst M, Pages H, Riemann JF, Eickhoff A, Raulf F, Kolbert G (2010) Fecal incontinence: part 4 of a series of articles on incontinence. Dtsch Arztebl Int 107(34-35):596-601. doi:10.3238/ arztebl.2010.0596

5. Telford KJ, Faulkner G, Hosker GL, Kiff ES, Hill J (2004) The strength duration test: a novel tool in the identification of occult neuropathy in women with pelvic floor dysfunction. Colorectal Dis 6(6):442-445. doi:10.1111/j.1463-1318.2004.00666.x

6. Ohlsson BL (1988) Effects of some different pulse parameters on the perception of intravaginal and intra-anal electrical stimulation. Med Biol Eng Comput 26(5):503-508

7. Suhel P, Kralj B, Plevnik S (1978) Advances in nonimplantable electrical stimualtors for correction of urinary incontinence. TIT J Life Sci 8(1-2):11-16

8. Plevnik S, Janez J (1979) Maximal electrical stimulation for urinary incontinence: report of 98 cases. Urology 14(6):638-645

9. Bergmann S, Eriksen BC (1986) Anal electrostimulation in urinary incontinence. Technical description of a new device. Urol Int 41(6):411-417

10. Green RJ, Laycock J (1990) Objective methods for evaluation of interferential therapy in the treatment of incontinence. IEEE Trans Biomed Eng 37(6):615-623. doi:10.1109/10.55665

11. Schwandner T, Hemmelmann C, Heimerl T, Kierer W, Kolbert G, Vonthein R, Weinel R, Hirschburger M, Ziegler A, Padberg W (2011) Triple-target treatment versus low-frequency electrostimulation for anal incontinence - a randomized controlled trial. Dtsch Arztebl Int 108(39):653-660. doi:10.3238/arztebl.2011.0653

12. Monk DN, Mills P, Jeacock J, Deakin M, Cowie A, Kiff ES (1998) Combining the strength-duration curve of the external anal sphincter with manometry for the assessment of faecal incontinence. Br J Surg 85(10):1389-1393. doi:10.1046/j. 1365-2168.1998.00956.x

13. Ziegler A, Heimerl A, Krockenberger K, Hemmelmann C (2012) Utility of medical devices: approaches to planning and conducting clinical trials. Z Evid Fortbild Qual Gesundhwes 106(5):322-331. doi:10.1016/j.zefq.2012.05.003

14. Heymen S, Scarlett Y, Jones K, Ringel Y, Drossman D, Whitehead WE (2009) Randomized controlled trial shows biofeedback to be superior to pelvic floor exercises for fecal incontinence. Dis Colon Rectum 52(10):1730-1737. doi:10. 1007/DCR.0b013e3181b55455

15. Pilkington SA (2010) The role of biofeedback in improving continence after anterior resection. Interventionale Studie, University of Southampton, School of Medicine

16. Healy CF, Brannigan AE, Connolly EM, Eng M, O'Sullivan MJ, McNamara DA, Cusack C, Deasy JM (2006) The effects of lowfrequency endo-anal electrical stimulation on faecal incontinence: a prospective study. Int J Colorectal Dis 21(8):802-806. doi:10.1007/ s00384-006-0102-0
17. Hosker G, Cody JD, Norton CC (2007) Electrical stimulation for faecal incontinence in adults. Cochrane Database Syst Rev (3): CD001310. doi:10.1002/14651858.CD001310.pub2

18. Norton C, Chelvanayagam S, Wilson-Barnett J, Redfern S, Kamm MA (2003) Randomized controlled trial of biofeedback for fecal incontinence. Gastroenterology 125(5):1320-1329. doi:10.1016/j. gastro.2003.09.039

19. Norton C, Cody JD (2012) Biofeedback and/or sphincter exercises for the treatment of faecal incontinence in adults. Cochrane Database Syst Rev 7, CD002111. doi:10.1002/14651858.CD002111.pub3

20. Atkins D, Best D, Briss PA, Eccles M, Falck-Ytter Y, Flottorp S, Guyatt GH, Harbour RT, Haugh MC, Henry D, Hill S, Jaeschke R, Leng G, Liberati A, Magrini N, Mason J, Middleton P, Mrukowicz J, O'Connell D, Oxman AD, Phillips B, Schünemann HJ, Edejer TT, Varonen H, Vist GE, Williams JW Jr, Zaza S (2004) Grading quality of evidence and strength of recommendations. Bmj 328(7454):1490. doi:10.1136/bmj.328.7454.1490

21. Higgins JPT, Green S, Cochrane Collaboration (2008) Cochrane Handbook for Systematic Reviews of Interventions. WileyBlackwell, Chichester

22. Piepho HP, Williams ER, Madden LV (2012) The use of two-way linear mixed models in multitreatment meta-analysis. Biometrics 88(4):1269-1277. doi:10.1111/j.1541-0420.2012.01786.x

23. Braun J, Willis S (2004) Fecal incontinence. Chirurg 75(9):871881. doi:10.1007/s00104-004-0923-8

24. Coulter ID, Favreau JT, Hardy ML, Morton SC, Roth EA, Shekelle P (2002) Biofeedback interventions for gastrointestinal conditions: a systematic review. Altern Ther Health Med $8(3): 76-83$

25. Enck P, Van der Voort IR, Klosterhalfen S (2009) Biofeedback therapy in fecal incontinence and constipation. Neurogastroenterol Motil 21(11):1133-1141. doi:10.1111/j.1365-2982.2009.01345.x

26. Geile D, Osterholzer G, Rosenberg R (2004) Diagnostics and conservative treatment of anal incontinence. Wien Med Wochenschr 154(3-4):76-83

27. Hay-Smith J, Mørkved S, Fairbrother KA, Herbison GP (2008) Pelvic floor muscle training for prevention and treatment of urinary and faecal incontinence in antenatal and postnatal women. Cochrane Database Syst Rev 4:CD007471. doi:10.1002/ 14651858.CD007471

28. Heymen S, Jones KR, Ringel Y, Scarlett Y, Whitehead WE (2001) Biofeedback treatment of fecal incontinence: a critical review. Dis Colon Rectum 44(5):728-736. doi:10.1007/BF02234575

29. Kroesen AJ, Buhr HJ (2003) Biofeedback in faecal incontinence. Chirurg 74(1):33-41. doi:10.1007/s00104-002-0567-5

30. Norton C, Kamm MA (2001) Anal sphincter biofeedback and pelvic floor exercises for faecal incontinence in adults-a systematic review. Aliment Pharmacol Ther 15(8):1147-1154. doi:10.1046/j. 1365-2036.2001.01039.x

31. Norton C (2004) Behavioral management of fecal incontinence in adults. Gastroenterology 126(1 Suppl 1):S64-S70. doi:10.1053/j. gastro.2003.10.058

32. Norton C (2008) Fecal incontinence and biofeedback therapy. Gastroenterol Clin North Am 37(3):587-604. doi:10.1016/j.gtc. 2008.06.008, viii

33. Norton C, Whitehead WE, Bliss DZ, Harari D, Lang J (2010) Management of fecal incontinence in adults. Neurourol Urodyn 29(1):199-206. doi:10.1002/nau.20803

34. Pares D, Norton C, Chelvanayagam S (2008) Fecal incontinence: the quality of reported randomized, controlled trials in the last ten years. Dis Colon Rectum 51(1):88-95. doi:10.1007/s10350-007-9146-7

35. Wald A (2003) Biofeedback for fecal incontinence. Gastroenterology 125(5):1533-1535. doi:10.1016/j.gastro.2003.09.007

36. Birkner B, Schepp W, Pehl C, Cluss B, Bittmann W, Emmert H, Fuchs M, Passern J, Wendl B, Heitland W (2000) Fecal incontinence. Diagnostic and therapeutic step scheme. Dtsch Arztebl 97(19):1302-1308 
37. Fernandez-Fraga X, Azpiroz F, Aparici A, Casaus M, Malagelada JR (2003) Predictors of response to biofeedback treatment in anal incontinence. Dis Colon Rectum 46(9):1218-1225. doi:10.1097/ 01.DCR.0000084337.15575.26

38. Guillemot F, Bouche B, Gower-Rousseau C, Chartier M, Wolschies E, Lamblin MD, Harbonnier E, Cortot A (1995) Biofeedback for the treatment of fecal incontinence. Long-term clinical results. Dis Colon Rectum 38(4):393-397. doi:10.1007/BF02054228

39. Kienle P, Weitz J, Koch M, Benner A, Herfarth C, Schmidt J (2003) Biofeedback versus electrostimulation in treatment of anal sphincter insufficiency. Dig Dis Sci 48(8):1607-1613. doi:10.1023/ A:1024728210036

40. Lacima G, Pera M, Amador A, Escaramis G, Piqué JM (2010) Long-term results of biofeedback treatment for faecal incontinence: a comparative study with untreated controls. Colorectal Dis 12(8):742-749. doi:10.1111/j.1463-1318.2009.01881.x

41. Loening-Baucke V (1990) Efficacy of biofeedback training in improving faecal incontinence and anorectal physiologic function. Gut 31(12):1395-1402

42. Lorenz EP, Wondzinski A (1996) Results of conservative and surgical therapy of anal incontinence. 1974 to 1992 patient sample. Zentralbl Chir 121(8):669-675

43. MacLeod JH (1987) Management of anal incontinence by biofeedback. Gastroenterology 93(2):291-294

44. Menard C, Trudel C, Cloutier R (1997) Anal reeducation for postoperative fecal incontinence in congenital diseases of the rectum and anus. J Pediatr Surg 32(6):867-869

45. Musial F, Hinninghofen H, Frieling T, Enck P (2000) Therapy of fecal incontinence in elderly patients: Study of a home biofeedback training program. Z Gerontol Geriatr 33(6):447-453

46. Nicastro A, Stella LP, Nicolai AP (2006) Fecal incontinence: role of anal sphincter rehabilitation. Chir Ital 58(4):493-500

47. Osterberg A, Graf W, Eeg-Olofsson K, Hallden M, Pahlman L (1999) Is electrostimulation of the pelvic floor an effective treatment for neurogenic faecal incontinence? Scand J Gastroenterol 34(3):319-324

48. Pager CK, Solomon MJ, Rex J, Roberts RA (2002) Long-term outcomes of pelvic floor exercise and biofeedback treatment for patients with fecal incontinence. Dis Colon Rectum 45(8):9971003

49. Privitera AC, Oliveri CE, Randazzo G, Ohazuruike NL, Prumeri S, Politi A, Succi L (2009) Biofeedback therapy for faecal incontinence: our experience. Chir Ital 61(2):149-154

50. Rieger NA, Wattchow DA, Sarre RG, Cooper SJ, Rich CA, Saccone GT, Schloithe AC, Toouli J, McCall JL (1997) Prospective trial of pelvic floor retraining in patients with fecal incontinence. Dis Colon Rectum 40(7):821-826. doi:10.1007/BF02055440

51. Ryn AK, Morren GL, Hallbook O, Sjodahl R (2000) Long-term results of electromyographic biofeedback training for fecal incontinence. Dis Colon Rectum 43(9):1262-1266. doi:10.1007/ BF02237433

52. Shafik A, Ahmed I, El-Sibai O, Mostafa RM (2003) Percutaneous peripheral neuromodulation in the treatment of fecal incontinence. Eur Surg Res 35(2):103-107. doi:10.1159/000069399

53. Solomon MJ, Rex J, Eyers AA, Stewart P, Roberts R (2000) Biofeedback for fecal incontinence using transanal ultrasonography: novel approach. Dis Colon Rectum 43(6):788-792. doi:10. 1007/BF02238015

54. Sprakel B, Maurer S, Langer M, Diller R, Spiegel HU, Winde G (1998) Value of electrotherapy within the scope of conservative treatment of anorectal incontinence. Zentralbl Chir 123(3):224-229

55. Surh S, Kienle P, Stern J, Herfarth C (1998) Passive electrostimulation therapy of the anal sphincter is inferior to active biofeedback training. Langenbecks Arch Chir Suppl Kongressbd 115:976-978
56. Terra MP, Dobben AC, Berghmans B, Deutekom M, Baeten CG, Janssen LW, Boeckxstaens GE, Engel AF, Felt-Bersma RJ, Slors JF, Gerhards MF, Bijnen AB, Everhardt E, Schouten WR, Bossuyt PM, Stoker J (2006) Electrical stimulation and pelvic floor muscle training with biofeedback in patients with fecal incontinence: a cohort study of 281 patients. Dis Colon Rectum 49(8):11491159. doi:10.1007/s10350-006-0569-3

57. Uludag O, Darby M, Dejong CHC, Schouten WR, Baeten CGMI (2002) Sacral neuromodulation is effective in the treatment of fecal incontinence with intact sphincter muscles; a prospective study. Ned Tijdschr Geneeskd 146(21):989-993

58. Whitehead WE, Burgio KL, Engel BT (1985) Biofeedback treatment of fecal incontinence in geriatric patients. J Am Geriatr Soc 33(5):320-324

59. Willis S, Holzl F, Fackeldey V, Schumpelick V (2004) Effect of biofeedback and electrostimulation on sphincter function in fecal incontinence. Zentralbl Chir 129(3):211-215. doi:10.1055/s-2004822743

60. Ho Y-H, Bartlett L (2006) A randomized study to evaluate the effects of supplementary home biofeedback guided pelvic floor and anal squeeze exercises in the treatment of faecal incontinence to reduce bowel leakage and improve patient quality of life. Available via WHO ICTRP. www.anzetr.org.au/ACTRN12606000070538.aspx. Accessed Oct 2, 2012

61. Leung FW (2011) Treatment of Patients With Fecal Incontinence. ClinicalTrials.gov. http://www.clinicaltrials.gov/show/ NCT00292318. Accessed 02 Oct 2012

62. Solomon M (2005) Randomized control trial of biofeedback guided pelvic floor exercises in the treatment in faecal incontinence. www. anzctr.org.au/ACTRN12605000747628.aspx. Accessed 02 Oct 2012

63. Vonen B (2006) A randomized, controlled, clinical trial of biofeedback and anal injections as first treatment of fecal incontinence. Available via WHO ICTRP. http://clinicaltrials.gov/show/ NCT00303030. Accessed 02 Oct 2012

64. Jorge JM, Wexner SD, Morgado PJ Jr, James K, Nogueras JJ, Jagelman DG (1994) Optimization of sphincter function after the ileoanal reservoir procedure. A prospective, randomized trial. Dis Colon Rectum 37(5):419-423. doi:10.1007/BF02076184

65. Latimer PR, Campbell D, Kasperski J (1984) A components analysis of biofeedback in the treatment of fecal incontinence. Biofeedback Self Regul 9(3):311-324

66. Miner PB, Donnelly TC, Read NW (1990) Investigation of mode of action of biofeedback in treatment of fecal incontinence. Dig Dis Sci 35(10):1291-1298. doi:10.1007/BF01536422

67. Bols E, Berghmans B, de Bie R, Govaert B, van Wunnik B, Heymans M, Hendriks E, Baeten C (2012) Rectal balloon training as add-on therapy to pelvic floor muscle training in adults with fecal incontinence: a randomized controlled trial. Neurourol Urodyn 31(1):132-138. doi:10.1002/nau.21218

68. Caldarella MP, Serio M, Milano A, Balatsinou C, Laterza F, Neri M (2008) Randomized controlled trial of biofeedback, electrical stimulation, and biofeedback plus electrical stimulation in patients with severe fecal incontinence after colo-anal anastomosis. Gastroenterology 134(4, Supplement 1):A-283. doi:10.1016/S0016-5085(08) 61314-1

69. Schnelle JF, Leung FW, Rao SS, Beuscher L, Keeler E, Clift JW, Simmons S (2010) A controlled trial of an intervention to improve urinary and fecal incontinence and constipation. J Am Geriatr Soc 58(8):1504-1511. doi:10.1111/j.1532-5415.2010.02978.x

70. Naimy N, Lindam AT, Bakka A, Faerden AE, Wiik P, Carlsen E, Nesheim BI (2007) Biofeedback vs. electrostimulation in the treatment of postdelivery anal incontinence: a randomized, clinical trial. Dis Colon Rectum 50(12):2040-2046. doi:10.1007/s10350-0079075-5

71. Bartlett L, Sloots K, Nowak M, Ho YH (2011) Biofeedback for fecal incontinence: a randomized study comparing exercise 
regimens. Dis Colon Rectum 54(7):846-856. doi:10.1007/DCR. 0b013e3182148fef

72. Schwandner T, König IR, Heimerl T, Kierer W, Roblick M, Bouchard R, Unglaube T, Holch P, Ziegler A, Kolbert G (2010) Triple target treatment (3T) is more effective than biofeedback alone for anal incontinence: the 3T-AI study. Dis Colon Rectum 53(7):10071016. doi:10.1007/DCR.0b013e3181db7738

73. Fynes MM, Marshall K, Cassidy M, Behan M, Walsh D, O'Connell PR, O'Herlihy C (1999) A prospective, randomized study comparing the effect of augmented biofeedback with sensory biofeedback alone on fecal incontinence after obstetric trauma. Dis Colon Rectum 42(6):753-758. doi:10.1007/BF02236930

74. Mahony RT, Malone PA, Nalty J, Behan M, O'Connell PR, O'Herlihy C (2004) Randomized clinical trial of intra-anal electromyographic biofeedback physiotherapy with intra-anal electromyographic biofeedback augmented with electrical stimulation of the anal sphincter in the early treatment of postpartum fecal incontinence. Am J Obstet Gynecol 191(3):885-890. doi:10.1016/j.ajog.2003.10.040

75. Ilnyckyj A, Fachnie E, Tougas G (2005) A randomized-controlled trial comparing an educational intervention alone vs education and biofeedback in the management of faecal incontinence in women. Neurogastroenterol Motil 17(1):58-63. doi:10.1111/j.1365-2982. 2004.00611.x

76. Heymen S, Pikarsky AJ, Weiss EG, Vickers D, Nogueras JJ, Wexner SD (2000) A prospective randomized trial comparing four biofeedback techniques for patients with faecal incontinence. Colorectal Dis 2(2):88-92. doi:10.1046/j.1463-1318. 2000.0136a.x

77. Solomon MJ, Pager CK, Rex J, Roberts R, Manning J (2003) Randomized, controlled trial of biofeedback with anal manometry, transanal ultrasound, or pelvic floor retraining with digital guidance alone in the treatment of mild to moderate fecal incontinence. Dis Colon Rectum 46(6):703-710. doi:10.1007/ s10350-004-6643-9

78. Norton C, Gibbs A, Kamm MA (2005) Randomized, controlled trial of anal electrical stimulation for fecal incontinence. Dis Colon Rectum 49(2):190-196. doi:10.1007/s10350-005-0251-1

79. Naimy N, Lindam AT, Bakka A, Faerden AE, Wiik P, Carlsen E, Nesheim B-I (2007) Biofeedback vs. electrostimulation in the treatment of postdelivery anal incontinence: a randomized, clinical trial. Dis Colon Rectum 50(12):2040-2046. doi:10.1007/s10350-007-9075-5
80. Ziegler A, Schwandner T (2013) Triple target treatment (3T) vs. biofeedback. Dis Colon Rectum 56(3):e35-e36. doi:10.1097/DCR. 0b013e31827d 1283

81. Norton C (2001) Biofeedback for faecal incontinence. Available via WHO ICTRP. http://www.controlled-trials.com/ISRCTN45147456. Accessed 2 May 2011

82. Norton C (2001) Randomised controlled trial of anal electrical stimulation in adults with faecal incontinence. Available via WHO ICTRP. www.controlled-trials.com/ISRCTN92215924. Accessed 2 May 2011

83. Whitehead WE (2005) Biofeedback for Fecal Incontinence. Available via WHO ICTRP. http://clinicaltrials.gov/show/NCT00124904. Accessed 2 May 2011

84. Schwandner T (2009) Prospektive randomisierte Studie zur konservativen Therapie der analen Inkontinenz mit Drei-ZieleBehandlung (3T) vs. niederfrequente Elektrostimulation (NFS). DRKS00000138. https://drks-neu.uniklinik-freiburg.de/drks_web/navigate.do?navigationId=trial.HTML\&TRIAL ID=DRKS00000138.

85. Schwandner T (2010) Prospective, randomized multicenter study to assess the outcome of conservative $3 \mathrm{~T}$ treatment with EMGbiofeedback. NCT00525291. http://clinicaltrials.gov/show/ NCT00525291. Accessed 2 May 2011

86. Bartlett L, Ho C (2010) A randomised clinical study was designed to compare two exercise regimen and determine the effect of an information session on the subjective rating of the symptoms of faecal incontinence and quality of life. ACTRN12610000258055. www. anzctr.org.au/ACTRN12610000258055.aspx. Accessed 20 Nov 2011

87. Weimann D (2011) Triple target treatment. Coloproctology 33:252-254. doi:10.1007/s00053-011-0204-1

88. Norton C (2010) Triple target treatment versus biofeedback. Dis Colon Rectum 53(7):971-972. doi:10.1007/DCR.0b013e3181ddc2f0

89. Rockwood TH, Church JM, Fleshman JW, Kane RL, Mavrantonis C, Thorson AG, Wexner SD, Bliss D, Lowry AC (2000) Fecal incontinence quality of life scale: quality of life instrument for patients with fecal incontinence. Dis Colon Rectum 43(1):9-16. doi:10.1007/BF02237236, discussion 16-17

90. Schwandner T, Hemmelmann C, Heimerl T, Kierer W, Kolbert G, Vonthein R, Weinel R, Hirschburger M, Ziegler A, Padberg W (2011) Triple-target treatment versus low-frequency electrostimulation for anal incontinence. Dtsch Arztebl Int 108(39):653-660. doi:10.3238/ arztebl.2011.0653 